\title{
Morphometric characterization of three Tsetse Fly Species - Glossina M. Morsitans, G. P. Palpalis and G. Tachinoides (Diptera: Glossinidae) from Ghana
}

\author{
Edwin Idriss Mustapha ${ }^{1,2 *}$, Maxwell Kelvin Billah ${ }^{3}$, Alexander Agyir- Yawson ${ }^{4}$ \\ ${ }^{1}$ African Regional Postgraduate Programme in Insect Science (ARPPIS), University of Ghana, Legon-Accra, Ghana \\ ${ }^{2}$ Sierra Leone Agricultural Research Institute, (SLARI) PMB 1313, Tower Hill, Freetown, Sierra Leone \\ ${ }^{3}$ Animal Biology and Conservation Science, University of Ghana, Box LG 67, Legon-Accra Ghana \\ ${ }^{4}$ Ghana Atomic Energy Commission, Accra, Ghana
}

\begin{abstract}
Tsetse flies (Diptera: Glossinidae) are the main vectors of Human African Trypanosomiasis (HAT), or sleeping sickness and Animal African Trypanosomiasis, (AAT) or Nagana in Sub Saharan Africa. In Ghana, whilst HAT is no longer a major public health issue, AAT is still widely reported and causes considerable losses in the livestock sector resulting in major impacts on agricultural production, livelihoods and food security in the country.

Application of morphometric techniques can reveal the existing level of population differentiation in tsetse flies, providing guidance on the distribution of genetically defined subpopulations. Morphometric techniques were used to compare size and shape of three tsetse fly speciesG. m. morsitans, G. p. palpalis and G. tachinoides of Ghana, and also compare populations of G. p. palpalis collected from three geographical regions (Northern, Eastern and Western) of Ghana.

Flies were sampled from four sites in the Western, one site in the Eastern and three sites in the Northern Region using standard un-baited biconical traps. Right wings and right hind legs of selected flies from different collection sites were removed and mounted on microscope slides using glycerin as the mounting medium. Images of the prepared slides were captured under a Leica EZ4 D microscope with an inbuilt camera connected to a laptop.
\end{abstract}

Linear and proportions of wing and hind tibia measurements were arcsine-root transformed before analyzing with a general linear model in analysis of variance (ANOVA). Multivariate statistical analyses were used to detect any possible variations.

Results of the GLM analyses of linear and ratio data revealed that different linear combinations can be used to characterize tsetse species of different populations. The ratio value hind tibia/wing length (th/at) significantly distinguished fly populations into four groups, Northern, Eastern, Western and the lab colony; this is an indication that hind tibia/wing length is a good morphometric feature which can be used to discriminate flies from different regions of Ghana.

The principal components and canonical variates as well as Mahalanobis squared distances confirmed linear and ratio separations. Therefore based on these differences in morphometric characters observed, the three tsetse species were distinguished from each other.

Similar work on morphometrics needs to be done to include more regions and many other body parts such as proboscis length, antennal length, thorax and abdomen length and width in order to establish stronger morphometric tools for discriminating different tsetse fly species.

Keywords - Characterization, Ghana, Morphometric, Tsetse Fly, Wing length.

\section{INTRODUCTION}

1.1 Background

Tsetse flies (Diptera: Glossinidae) are the main vectors of Human African Trypanosomiasis (HAT) or sleeping sickness and Animal African Trypanosomiasis (AAT) or nagana in Sub-Saharan Africa (SSA) [1,2]. AAT is widely reported in Ghana and causes considerable losses in the livestock sector resulting in major impacts on agricultural production, livelihoods and food security in the country [3, 4].

A variety of vector control techniques may be used in order to reduce tsetse fly populations, including the use of insecticide-impregnated traps and targets, live-bait application, sequential aerial spraying with pyrethriod, and sterile insect release (SIT) [5,6,7]. 
Morphometric techniques aim at measuring size, shape, and the relationship between size and shape (allometry) [8], and have become one of the major tools for the study of population structures of insect vectors [9].

Besides its evident contribution to insect systematics, the main epidemiological contribution of morphometrics to medical entomology has been to help decision making in the development of vector control strategies $[10,11,12]$. In the current study, we use a morphometric approach to examine the possible differences that may exist between different populations of tsetse fly species of Ghana.

The objective of this research was to apply morphometric analyses to check for size and shape differences among three species of tsetse flies- G. $p$. palpalis, G. m. morsitans and G. tachinoides in Ghana.

\section{MATERIALS AND METHODS}

\subsection{Study area}

The study areas comprised of four sites in the Western Region, one site in the Eastern Region and three sites in the Northern Region (Figure 1). These sites were geo- referenced (Table 1) using a handheld Global Positioning System (eTrex ${ }^{\circledR}$ LEGEND C GARMIN).

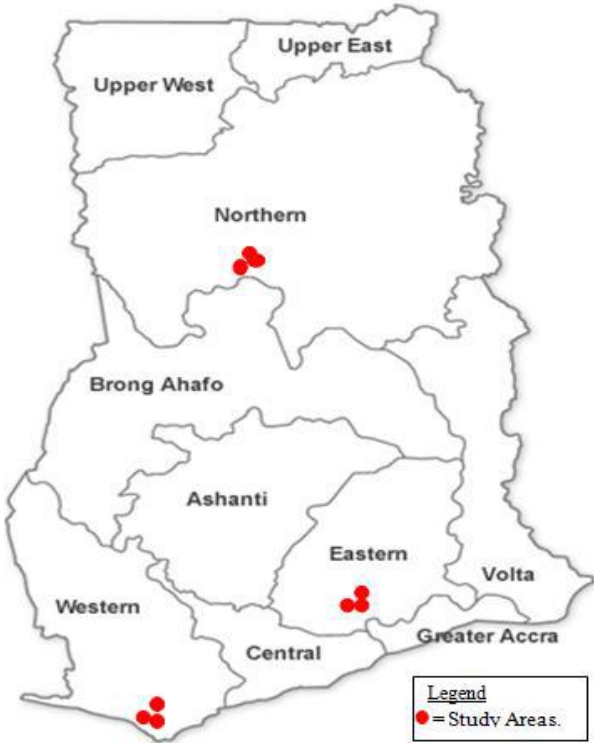

Fig.1: Map of Ghana showing various sampling sites in the three regions.

Table.1: Collection sites, geographic coordinates and number of slides prepared per site.

\begin{tabular}{|c|c|c|c|c|c|c|c|c|}
\hline \multirow[t]{3}{*}{$\overline{\text { Region }}$} & \multirow[t]{3}{*}{ District } & \multirow[t]{3}{*}{ Site } & \multirow[t]{3}{*}{ Site Code } & \multirow{2}{*}{\multicolumn{2}{|c|}{$\begin{array}{l}\text { GPS } \\
\text { Coordinates }\end{array}$}} & & \multicolumn{2}{|c|}{ Slides Prepared } \\
\hline & & & & & & & & \\
\hline & & & & Lat-N & Long-W & Altitude (m) & $\mathrm{M}$ & $\mathrm{F}$ \\
\hline Eastern & Suhum & Tomem & TMM & $05.97661^{0}$ & $000.36671^{0}$ & 140 & 20 & 25 \\
\hline \multirow[t]{3}{*}{ Northern } & West Mamprusi & Bogdoo & BOG & $10.23878^{\circ}$ & $00.71902^{\circ}$ & 119 & 06 & 09 \\
\hline & North Gonja & Daboya & DAB & $09.29785^{\circ}$ & $01.51569^{\circ}$ & 108 & 08 & 18 \\
\hline & Savelugu/Nanton & Kuldanali & KUL & $09.68993^{\circ}$ & $00.97743^{\circ}$ & 103 & 04 & 14 \\
\hline \multirow[t]{4}{*}{ Western } & Jomoro & Alawule & ALW & $05.03849^{\circ}$ & $002.70271^{0}$ & 17 & 25 & 25 \\
\hline & & Ezinlibo & EZN & $05.01449^{\circ}$ & $002.72064^{0}$ & 20 & 25 & 25 \\
\hline & & Nawule & NAL & $05.03798^{\circ}$ & $002.72401^{0}$ & 16 & 25 & 25 \\
\hline & & Tikobo & TKB & $05.05396^{0}$ & $002.70091^{\circ}$ & 19 & 25 & 25 \\
\hline
\end{tabular}

\subsection{Entomological survey}

Tsetse flies were sampled in September, October and November, 2013 in the Western and Eastern Regions, and in April, 2014 in the Northern Region, using standard unbaited biconical traps with blue-black material. Traps were randomly set in tsetse fly favourable biotopes in four localities in the Jomoro District of the Western Region, one site in Suhum District of the Eastern Region, one site in Savelugu/Nanton District, another site in the West Mamprusi District and a third site in the North Gonji District (all of the Northern Region). Traps were set for periods of 1-3days per field visit, and flies collected twice daily.

In addition to the field collected samples, one other population, Glossina morsitans morsitans was kindly provided by the Ghana Atomic Energy Commission (GAEC) from their laboratory colony for comparative purposes. The laboratory colony was reared under optimal conditions and adult flies maintained at a temperature of $24^{\circ} \mathrm{C}$ and $70-80 \%$ relative humidity.

\subsection{Slide preparation, image capture and measurement}

Based on the number of specimens available, 50 flies (25 females and 25 males) each from Tikobo (TKB), Nawule (NAL), Ezinlibo (EZN) and Alawule (ALW) in the Western 
Region; 45 flies (25 females and 20 males) from Tomem (TMM) in the Eastern Region; 25 flies (17 females and 8 males) from Bogdoo (BOG), 15 flies (9 females and 6 males) from Kuldanah (KUL), 18 flies (14 females and 4 males) from Daboya (DAB) in the Northern Region, and 100 flies (50 females and 50 males) from the laboratory colony were randomly selected for slide preparation. The right forewings and right hind legs of selected flies were carefully removed from the thorax, using two pairs of fine curved Swiss forceps, and temporary slide mounts were prepared of the detached wings and legs of the flies.

Images of the prepared slides were captured under a Leica EZ4 D microscope with an inbuilt camera connected to a laptop. From the digital pictures, sixteen landmarks on the wing were selected in Leica (vision 8.0) to represent unambiguous homologous locations on all specimens [13], and distances between the landmarks were computed to characterize the wing as estimations of size and shape differentiation in the specimens.

\subsection{Data analysis}

Linear and proportions of wing and hind tibia measurements were arcsine-root transformed before analyzing with a general linear model (PROC GLM, SAS Institute Inc., 2001) in analysis of variance (ANOVA). When ANOVAs were significant $(\mathrm{P}=0.05)$, the means were separated using the Student-Newman-Keuls (SNK) test $[14,15,16,17]$. All data metrices were $\log 10$ transformed first before the statistical treatment. Multivariate statistical analysis i.e., analysis of variance, principal components analysis and canonical analysis were used to detect any possible variations. All morphometric analyses were performed using Statistical Analysis System software version 8.2 (SAS Institute Inc., 2001). Wing and hind tibia measurements were analyzed separately to allow covariances between distances, sexes and species to interact in a more meaningful way [14].

\section{RESULTS}

3.1 Size comparison of three tsetse fly species of Ghana Many of the linear measurements showed significant differences, and separated the flies into various populations. Wing length (at) showed significant difference $(\mathrm{P}<0.0001)$ and partially separated the flies into four clusters, in which the lab colony (G. m. morsitans) stood out to be the largest, followed by the G. p. palpalis population from the Western region and the other two palpalis populations (G. p. palpalis from the Eastern and G. $p$. palpalis from the Northern Regions), being similar in size and smaller than G. p. palpalis from the Western but larger than G. tachinoides from the Northern Region (Table 2). The costa vein $(a b)$ was important and separated the lab colony ( $G$. m. morsitans) from $G$. tachinoides population as well as the three palpalis populations (G. p. palpalis populations from the Eastern and Western, and Northern Regions respectively), making it one of the distinguishing features that characterizes the three tsetse fly species (Table 2).

Linear combinations as ratios were important in separation of the fly populations into various species. There was significant difference $(\mathrm{P}<0.0001)$ among G. p. palpalis population from the Eastern, G. tachinoides population from the Northern and lab colony (G. m. morsitans) based on $g h / h i$ (hatchet blade line to outside length of hatchet cell) indicating that the three tsetse species, G. $m$. morsitans, G. p. palpalis and G. tachinoides can be morphologically characterized by this ratio value $g h / h i$ (Table 3).

Table.2: Mean linear measurements of three tsetse species (G. m. morsitans, G. p. palpalis and G. tachinoides) of Ghana Population

Mean Linear measurements $(\mathrm{mm})( \pm \mathrm{SE})$

\begin{tabular}{|c|c|c|c|c|c|c|c|c|c|c|}
\hline & at** & ww & $a b$ & $\mathrm{ac}$ & & $\mathrm{ad}$ & & ae & af & fg \\
\hline $\begin{array}{l}\text { G.p.palpalis } \\
\text { (Eastern) }\end{array}$ & $\begin{array}{c}7.405 \pm 0.094 \mathrm{c} \\
(65)\end{array}$ & $\begin{array}{c}* 2.856 \pm 0.028 \mathrm{a} \\
(65)\end{array}$ & $\begin{array}{c}3.128 \pm 0.032 b \\
(65)\end{array}$ & $\begin{array}{c}5.431 \pm 0.072 \mathrm{a} \\
(65)\end{array}$ & 6.408 & $\begin{array}{l} \pm 0.067 \mathrm{~b} \\
(65)\end{array}$ & 07.030 & $\begin{array}{l} \pm 0.073 \mathrm{a} \\
(65)\end{array}$ & $\begin{array}{c}7.246 \pm 0.072 \mathrm{a} \\
(65)\end{array}$ & $\begin{array}{c}2.198 \pm 0.031 \mathrm{a} \\
(65)\end{array}$ \\
\hline $\begin{array}{l}\text { G. m. morsitans } \\
\text { (Lab colony) }\end{array}$ & $\begin{array}{c}7.959 \pm 0.051 \mathrm{a} \\
(100)\end{array}$ & $\begin{array}{c}2.874 \pm 0.018 \mathrm{a} \\
(100)\end{array}$ & $\begin{array}{c}3.275 \pm 0.028 \mathrm{a} \\
(100)\end{array}$ & $\begin{array}{c}5.511 \pm 0.046 \mathrm{a} \\
(100)\end{array}$ & 6.558 & $\begin{array}{l} \pm 0.065 \mathrm{a} \\
(100)\end{array}$ & 7.220 & $\begin{array}{l} \pm 0.052 \mathrm{a} \\
(100)\end{array}$ & $\begin{array}{c}8.183 \pm 0.717 \mathrm{a} \\
(100)\end{array}$ & $\begin{array}{c}2.170 \pm 0.018 \mathrm{a} \\
(100)\end{array}$ \\
\hline G.p.palpalis & $7.436 \pm 0.117 \mathrm{c}$ & $2.639 \pm 0.047 \mathrm{~b}$ & $2.918 \pm 0.073 \mathrm{c}$ & $5.342 \pm 0.148 \mathrm{a}$ & 6.227 & $\pm 0.138 \mathrm{~b}$ & 6.648 & $\pm 0.117 \mathrm{~b}$ & $7.061 \pm 0.126 \mathrm{a}$ & $2.125 \pm 0.029 a$ \\
\hline (Northern) & (18) & (18) & (18) & (18) & & (18) & & (18) & (18) & (18) \\
\hline G. tachinoides & $6.915 \pm 0.092 \mathrm{~d}$ & $2.532 \pm 0.036 c$ & $2.783 \pm 0.040 \mathrm{~d}$ & $4.832 \pm 0.071 b$ & 5.853 & $\pm 0.079 \mathrm{c}$ & 6.372 & $\pm 0.074 \mathrm{c}$ & $6.592 \pm 0.086 a$ & $2.011 \pm 0.028 \mathrm{~b}$ \\
\hline (Northern) & (40) & (40) & (40) & (40) & & $(40)$ & & (40) & $(40)$ & (40) \\
\hline G.p.palpalis & $7.715 \pm 0.033 b$ & $2.874 \pm 0.011 \mathrm{a}$ & $3.052 \pm 0.018 b$ & $5.384 \pm 0.030 \mathrm{a}$ & 6.514 & $\pm 0.038 \mathrm{a}$ & 7.128 & $\pm 0.032 \mathrm{a}$ & $7.364 \pm 0.032 \mathrm{a}$ & $2.210 \pm 0.013 \mathrm{a}$ \\
\hline
\end{tabular}




\begin{tabular}{cllcclclcr} 
(Western) & & $(200)$ & $(200)$ & $(200)$ & $(200)$ & $(200)$ & $(200)$ & $(200)$ \\
F & 33.85 & 37.70 & 30.88 & 16.64 & 13.68 & 27.51 & 1.72 & 10.23 \\
df & 4,398 & 4,398 & 4,398 & 4,398 & 4,398 & 4,398 & 4,398 & 4,398 \\
P & $<0.0001$ & $<0.0001$ & $<0.0001$ & $<0.0001$ & $<0.0001$ & $<0.0001$ & 0.1448 & $<0.0001$ \\
\hline
\end{tabular}

Population

Mean Linear measurements $(\mathrm{mm})( \pm \mathrm{SE})$

\begin{tabular}{|c|c|c|c|c|c|c|c|c|c|c|}
\hline & $\mathrm{gh}^{* *}$ & & hi & ij & $\mathrm{jk}$ & & $\mathrm{kg}$ & $\mathrm{kl}$ & ho & th \\
\hline G.p.palpalis & $0.860 \pm 0.011 b^{*}$ & 2.560 & $\pm 0.028 \mathrm{a}$ & $0.165 \pm 0.003 \mathrm{ab}$ & $1.638 \pm 0.016 b$ & 1.452 & $\pm 0.016 \mathrm{a}$ & $0.327 \pm 0.005 b$ & $2.806 \pm 0.089 \mathrm{a}$ & $2.370 \pm 0.018 \mathrm{a}$ \\
\hline (Eastern) & (65) & & (65) & (65) & (65) & & (65) & (65) & (65) & (65) \\
\hline G. m. morsitans & $0.923 \pm 0.008 \mathrm{a}$ & $2.526 \pm$ & $\pm 0.019 \mathrm{ab}$ & $0.181 \pm 0.006 \mathrm{a}$ & $1.669 \pm 0.015 \mathrm{ab}$ & 1.472 & $\pm 0.012 \mathrm{a}$ & $0.318 \pm 0.003 b$ & $2.810 \pm 0.035 \mathrm{a}$ & $2.263 \pm 0.018 b$ \\
\hline (Lab colony) & (100) & & (100) & (100) & (100) & & (100) & (100) & (100) & (100) \\
\hline G.p.palpalis & $0.842 \pm 0.018 b$ & 2.453 & $\pm 0.037 \mathrm{~b}$ & $0.161 \pm 0.003 \mathrm{ab}$ & $1.749 \pm 0.175 \mathrm{a}$ & 0.337 & $\pm 0.009 \mathrm{c}$ & $1.378 \pm 0.028 \mathrm{a}$ & $2.593 \pm 0.068 b$ & $2.222 \pm 0.051 b$ \\
\hline (Northern) & (18) & & (18) & (18) & (18) & & (18) & (18) & (18) & (18) \\
\hline G. tachinoides & $0.793 \pm 0.013 c$ & 2.255 & $\pm 0.034 \mathrm{c}$ & $0.140 \pm 0.003 b$ & $1.485 \pm 0.019 \mathrm{c}$ & 1.254 & $\pm 0.023 \mathrm{~b}$ & $0.308 \pm 0.005 b$ & $2.499 \pm 0.038 b$ & $2.079 \pm 0.025 \mathrm{c}$ \\
\hline (Northern) & (40) & & (40) & (40) & (40) & & (40) & (40) & (40) & (40) \\
\hline G.p.palpalis & $0.896 \pm 0.005 \mathrm{a}$ & 2.608 & $\pm 0.013 \mathrm{a}$ & $0.183 \pm 0.004 \mathrm{a}$ & $1.650 \pm 0.007 b$ & 1.478 & $\pm 0.008 \mathrm{a}$ & $0.331 \pm 0.003 b$ & $2.836 \pm 0.013 \mathrm{a}$ & $2.408 \pm 0.008 \mathrm{a}$ \\
\hline (Western) & (200) & & $(20$ & & (200) & $(200)$ & & (200) & (200) & $(200)$ \\
\hline \multicolumn{11}{|l|}{$(200)$} \\
\hline $\mathrm{F}$ & 27.65 & 30.02 & & 6.59 & 8.66 & 428.69 & & 2736.14 & 11.87 & 54.25 \\
\hline $\mathrm{df}$ & 4,398 & 4,398 & & 4, 398 & 4,398 & 4,398 & & 4,398 & 4,398 & 4,398 \\
\hline $\mathrm{P}$ & $<0.0001$ & $<0.000$ & & $<0.0001$ & $<0.0001$ & $<0.000$ & & $<0.001$ & $<0.0001$ & $<0.0001$ \\
\hline
\end{tabular}

* Means in the same column followed by same letters are not significantly different (P=0.05), using Student-NewmanKeuls (SNK) test. ANOVA on arcsine-transformed proportion values

**Measurement code: at= wing length, ab=length of costal vein, ac= length of vein 1 , ad= length of vein 2 , ae $=$ length of vein 3 , af= length of vein $4, \mathrm{fg}=$ hatchet cell to wing tip, $\mathrm{gh}=$ basal height of hatchet cell, hi= outside length of hatchet cell, $\mathrm{ij}=$ apical height of hatchet cell, $\mathrm{jk}=$ hatchet handle, $\mathrm{kg}=$ hatchet blade line, $\mathrm{kl}=\mathrm{cross}$ vein $(\mathrm{r}-\mathrm{m})$, at $=\mathrm{wing}$ length, ww= wing width, ho= hatchet cell to lower end of the wing, $\mathrm{th}=$ hind tibia, $\mathrm{fg}=$ hatchet cell to posterior end of the wing Table.3: Mean ratio values of three tsetse species (G. m. morsitans, G. p. palpalis and G. tachinoides) from Ghana.

\begin{tabular}{|c|c|c|c|c|c|c|c|}
\hline \multirow[t]{2}{*}{ Population } & \multicolumn{7}{|c|}{ Meanproportion $(\mathrm{mm})( \pm \mathrm{SE})$} \\
\hline & $\mathrm{gh} / \mathrm{kg}^{* *}$ & $\mathrm{~kg} / \mathrm{hi}$ & gh/hi & $\mathrm{gh} / \mathrm{jk}$ & $\mathrm{jk} / \mathrm{hi}$ & ho/hi & $\mathrm{kl} / \mathrm{ho}$ \\
\hline G.p.palpalis & $1.689 \pm 0.005 \mathrm{a}^{*}$ & $1.757 \pm 0.003 \mathrm{c}$ & $2.976 \pm 0.003 \mathrm{a}$ & $1.905 \pm 0.004 a$ & $1.560 \pm 0.004 \mathrm{a}$ & $2.513 \pm 0.003 b$ & $3.106 \pm 0.004 b$ \\
\hline (Eastern) & (45) & (45) & (45) & (65) & (65) & (65) & (65) \\
\hline G. m. morsitans & $1.595 \pm 0.003 b$ & $1.715 \pm 0.003 \mathrm{~d}$ & $2.740 \pm 0.002 \mathrm{c}$ & $1.808 \pm 0.002 \mathrm{c}$ & $1.513 \pm 0.003 a$ & $2.398 \pm 0.003 b$ & $3.289 \pm 0.003 \mathrm{a}$ \\
\hline (Lab colony) & (100) & (100) & $(100)$ & $(100)$ & $(100)$ & $(100)$ & $(100)$ \\
\hline G.p.palpalis & $0.398 \pm 0.059 \mathrm{c}$ & $7.246 \pm 0.003 \mathrm{a}$ & $2.915 \pm 0.006 \mathrm{ab}$ & $1.934 \pm 0.024 \mathrm{a}$ & $1.395 \pm 0.076 b$ & $2.506 \pm 0.007 \mathrm{a}$ & $0.709 \pm 0.020 \mathrm{c}$ \\
\hline (Northern) & (18) & (18) & (18) & (18) & (18) & (18) & (18) \\
\hline G. tachinoides & $1.577 \pm 0.005 b$ & $1.799 \pm 0.003 b$ & $2.841 \pm 0.003 b$ & $1.876 \pm 0.004 b$ & $1.515 \pm 0.004 \mathrm{a}$ & $2.433 \pm 0.005 b$ & $2.985 \pm 0.005 b$ \\
\hline (Northern) & (40) & (40) & (40) & (40) & (40) & (40) & (40) \\
\hline $\begin{array}{l}\text { G.p. palpalis } \\
\text { (Western) }\end{array}$ & $\begin{array}{c}1.650 \pm 0.002 \mathrm{ab} \\
(200)\end{array}$ & $\begin{array}{c}1.764 \pm 0.002 \mathrm{c} \\
(200) \\
\end{array}$ & $\begin{array}{c}2.907 \pm 0.001 \mathrm{ab} \\
(200) \\
\end{array}$ & $\begin{array}{c}1.841 \pm 0.002 b c \\
(200)\end{array}$ & $\begin{array}{c}1.577 \pm 0.002 \mathrm{a} \\
(200) \\
\end{array}$ & $\begin{array}{c}2.538 \pm 0.002 \mathrm{a} \\
(200) \\
\end{array}$ & $\begin{array}{c}3.096 \pm 0.003 b \\
(200)\end{array}$ \\
\hline
\end{tabular}




$\begin{array}{llllllll}\text { F } & 4433.66 & 1421.53 & 30.45 & 9.35 & 7.36 & 14.59 & 3629.23 \\ \text { df } & 4,398 & 4,398 & 4,398 & 4,398 & 4,398 & 4,398 & 4,398 \\ \text { P } & <0.0001 & <0.0001 & <0.0001 & <0.0001 & <0.0001 & <0.0001 & <0.0001\end{array}$

Population

Mean proportion $(\mathrm{mm})( \pm \mathrm{SE})$

\begin{tabular}{|c|c|c|c|c|c|c|c|}
\hline & $\mathrm{kl} / \mathrm{kg} * *$ & $\mathrm{kl} / \mathrm{hi}$ & $\mathrm{kl} / \mathrm{jk}$ & ho/fg & $\mathrm{kg} / \mathrm{fg}$ & $\mathrm{gh} / \mathrm{fg}$ & ww/at \\
\hline G.p.palpalis & $4.425 \pm 0.003 \mathrm{a}^{*}$ & $7.813 \pm 0.002 \mathrm{a}$ & $5.00 \pm 0.003 a$ & $2.151 \pm 0.005 \mathrm{a}$ & $1.506 \pm 0.008 \mathrm{~b}$ & $2.545 \pm 0.005 \mathrm{a}$ & $2.584 \pm 0.003 \mathrm{~d}$ \\
\hline (Eastern) & (45) & (45) & (45) & (45) & (45) & (45) & (45) \\
\hline G. m. morsitans & $4.608 \pm 0.002 \mathrm{a}$ & $7.937 \pm 0.001 \mathrm{a}$ & $5.236 \pm 0.002 \mathrm{a}$ & $2.062 \pm 0.002 b$ & $1.472 \pm 0.003 b$ & $2.353 \pm 0.002 b$ & $2.770 \pm 0.002 b$ \\
\hline (Lab colony) & (100) & (100) & (100) & (100) & (100) & (100) & (100) \\
\hline G.p.palpalis & $0.244 \pm 0.076 b$ & $7.779 \pm 0.008 b$ & $1.181 \pm 0.039 b$ & $2.169 \pm 0.007 \mathrm{a}$ & $1.289 \pm 0.003 c$ & $2.525 \pm 0.007 \mathrm{a}$ & $2.817 \pm 0.004 a$ \\
\hline (Northern) & (18) & (18) & (18) & (18) & (18) & (18) & (18) \\
\hline G. tachinoides & $4.049 \pm 0.004 a$ & $7.299 \pm 0.002 \mathrm{c}$ & $4.808 \pm 0.003 a$ & $2.174 \pm 0.004 a$ & $1.605 \pm 0.005 a$ & $2.538 \pm 0.003 a$ & $2.732 \pm 0.003 c$ \\
\hline (Northern) & (40) & (40) & (40) & (40) & (40) & (40) & (40) \\
\hline G. p. palpalis & $4.444 \pm 0.002 \mathrm{a}$ & $7.874 \pm 0.001 \mathrm{a}$ & $4.950 \pm 0.002 \mathrm{a}$ & $2.146 \pm 0.002 \mathrm{a}$ & $1.492 \pm 0.003 \mathrm{a}$ & $2.463 \pm 0.002 \mathrm{a}$ & $2.681 \pm 0.001 \mathrm{c}$ \\
\hline (Western) & (200) & (200) & (200) & (200) & (200) & (200) & (200) \\
\hline $\mathrm{F}$ & 12799.4 & 3569.04 & 1160.31 & 12.11 & 779.54 & 22.01 & 25.94 \\
\hline $\mathrm{df}$ & 4,398 & 4,398 & 4,398 & 4,398 & 4,398 & 4,398 & 4,398 \\
\hline $\mathrm{P}$ & $<0.0001$ & $<0.0001$ & $<0.0001$ & $<0.0001$ & $<0.0001$ & $<0.0001$ & $<0.0001$ \\
\hline
\end{tabular}

3.2 Principal components and canonical variates analyses of three tsetse species of Ghana

All the 16 wing variables were subjected to principal component analysis (PCA) to reduce the number of dimensions and to find out major sources of variation. Projection of these wing variables on the first two principal axes showed a partial or fuzzy separation of the populations of different tsetse fly species (Figure 2a). The first two components accounted for $77.98 \%$ (PC1 + PC2 = $52.05 \%+25.93 \%$ ) of the total size variation and provided a reasonable approximation of the total amount of variation among the populations of the tsetse species. The third, fourth, and fifth components contributed $7.30 \%, 3.47 \%$ and $2.69 \%$ respectively, and did not improve in the separation of the species.

Projection of the data on first two canonical axes however, showed a similar separation trend among the five tsetse populations, with the five populations separated into two clusters; the two palpalis populations ( $G$. p. palpalis from the Eastern region and the Western region), lab colony ( $G$. $m$. morsitans) population, G. tachinoides population from the Northern clustered together, while the population of $G$. p. palpalis from the Northern was widely separated from the others and stood out alone along the negative PC1 axis (Figure 2b). The first two canonical variates contributed a total of $98.97 \%(\mathrm{CV} 1+\mathrm{CV} 2=97.65 \%+1.32 \%)$ to the total variance with the third and fourth variates contributing $0.74 \%$ and $0.29 \%$, respectively.

The Mahalanobis squared distances $\left(\mathrm{D}^{2}\right)$ of population was calculated to see the cohesiveness of members in a group and the closeness of the populations to each other. The biggest distance value $\left(\mathrm{D}^{2}=1567\right)$ was between $G . p$. palpalis population from the Eastern and G. p. palpalis from the Northern region, whereas the smallest distance was between G. p. palpalis (Eastern) and G. p. palpalis (Western) $\left(\mathrm{D}^{2}=3.1873\right)$. 


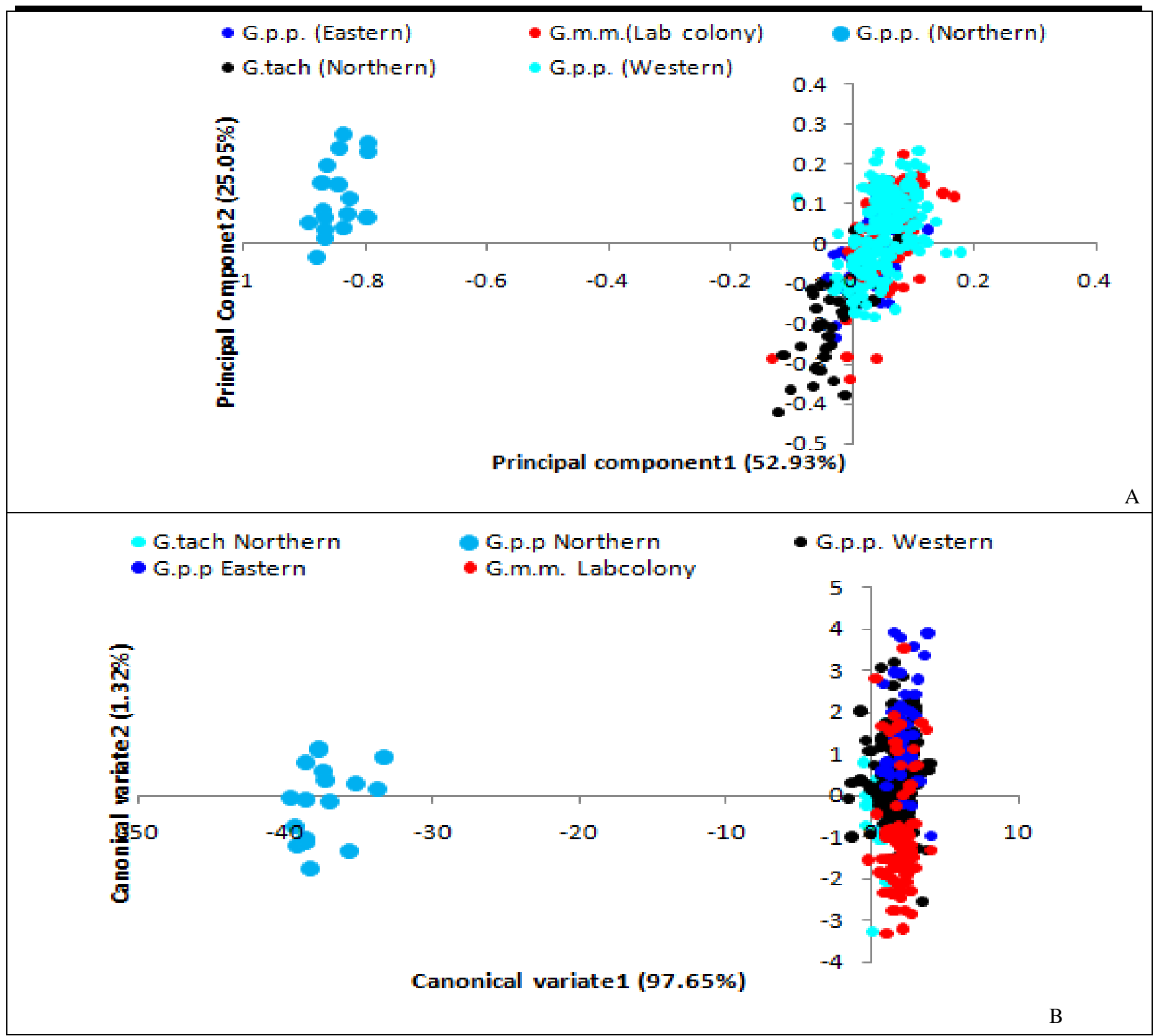

Fig.2: Projection of wing data of three species of tsetse flies of Ghana. (A) First two principal components (B) First two canonical variates

\subsection{Comparison of G. p. palpalis populations from three}

\section{Regions of Ghana}

Wing length $(a t)$ was significantly different $(\mathrm{P}<0.0001)$ and separated Eastern, Northern and Western populations from lab colony, whereas wing width $(w w)$ and hatchet blade line, $(\mathrm{kg})$ were important and separated G. p. palpalis of Eastern and Western populations together with laboratory colony from those of Northern Region (Table 2).

The ratio value, th/at (hind tibia/wing length) significantly $(\mathrm{P}<0.0001)$ separated fly populations into four groups,
Northern, Eastern, Western and the lab colony, an indication that hind tibia/wing length is a good discriminating tool (Table 3).

Wing data projected on the first five principal components showed a partial separation of G. p. palpalis collected from three regions in Ghana (Northern, Eastern and Western) and G. m. morsitans from laboratory colony (Figure 3a). The first two components contributed 76.63\% $(\mathrm{PC} 1+\mathrm{PC} 2=56 / 47 \%+19.16 \%)$, the third to fifth components respectively $(\mathrm{PC} 3+\mathrm{PC} 4+\mathrm{PC} 5=7.72 \%+$ 
$3.78 \%+2.94 \%$ ) contributed little in the separation of the flies from the different populations. Likewise projection of the data on the first two canonical variate axes showed a similar pattern of separation with four populations forming two clusters (Figure 3b), G. p. palpalis populations from the Eastern, Western regions and laboratory colony clustered together while G. p. palpalis from the Northern population distinctly separated from the other three populations. The first two canonical variates contributed $99.7 \%(\mathrm{CV} 1+\mathrm{CV} 2=98.38+1.32 \%)$.
Table.4: Mahalanobis squared distances $\left(D^{2}\right)$ between clusters representing flies, from different regions in Ghana.

\begin{tabular}{lllll}
\hline Region & Eastern & $\begin{array}{l}\text { Lab } \\
\text { colony }\end{array}$ & Northern & Western \\
\hline Eastern & 0 & & & \\
Lab & 9.323 & 0 & & \\
colony & & & 0 & \\
Northern & 1540 & 1519 & 1512 & 0 \\
Western & 3.13 & 3.93 & 15 & \\
\hline
\end{tabular}

The largest Mahalanobis squared distance $\left(\mathrm{D}^{2}=1540\right)$ was between Eastern and Northern, followed by Northern and Western $\left(D^{2}=1512\right)$, Eastern and laboratory colony $\left(D^{2}=\right.$ 9.32) and the lowest distance $\left(\mathrm{D}^{2}=3.92\right)$ being between laboratory colony and the Western (Table 4), an indication that flies from Western Region are more closely related to those of the laboratory colony than flies from the Northern and Eastern Regions.

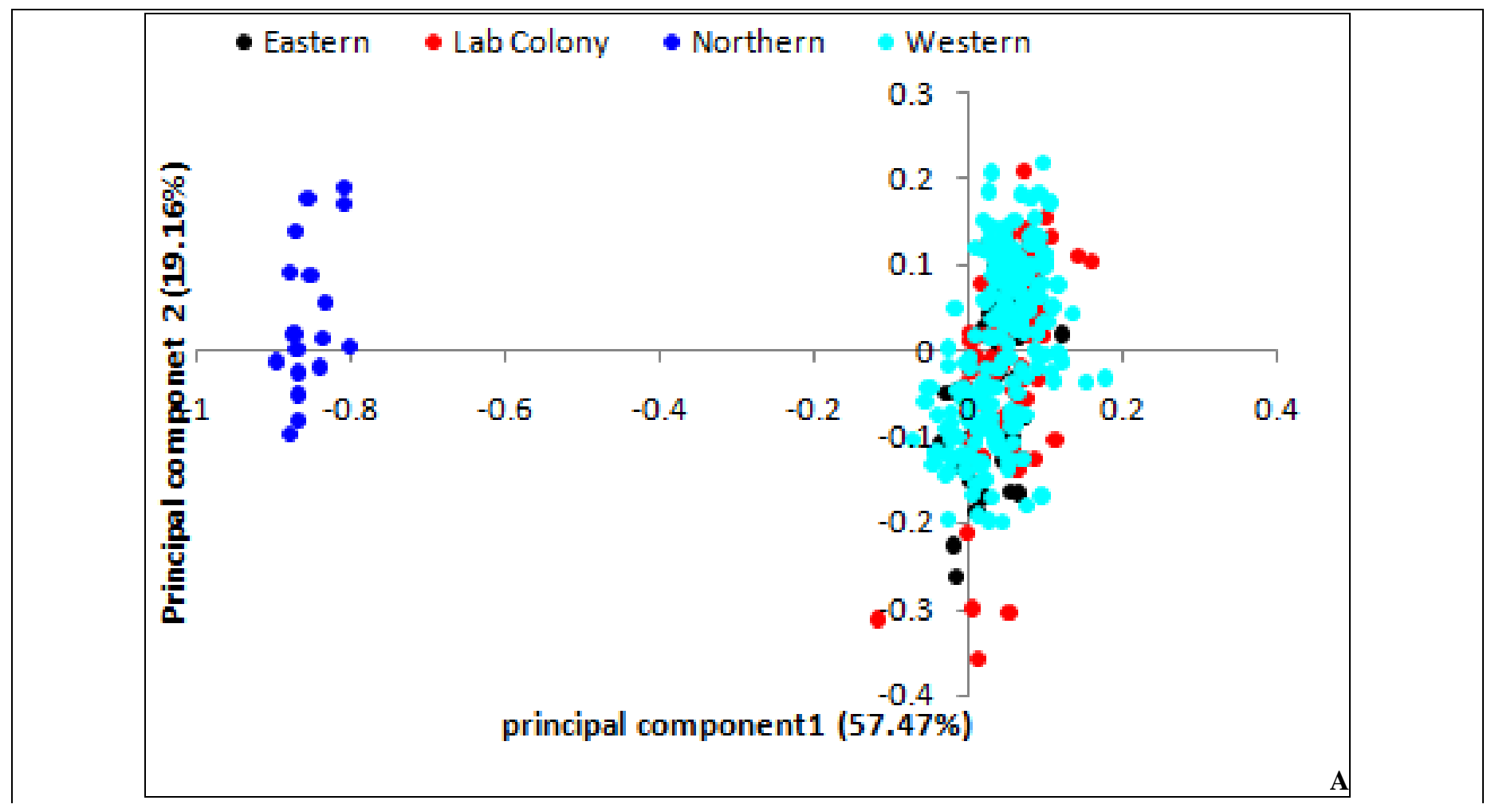




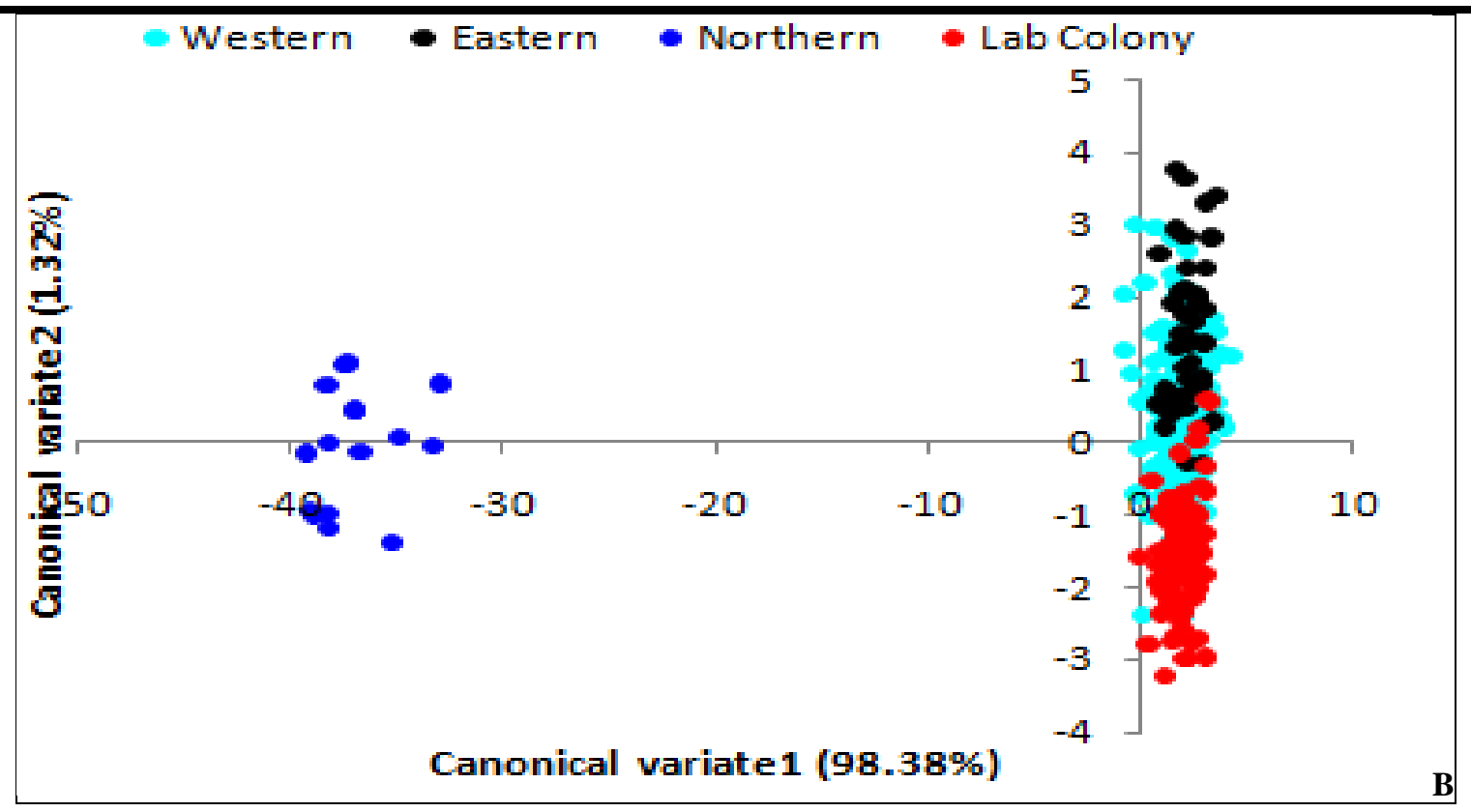

Fig.3: Projection of wing data of 263 G. p. palpalis sampled from Northern, Eastern and Western Regions and 100 G. $\mathrm{m}$. morsitans from lab colony (A) First two principal components (B) First two canonical variates of the flies

IV.

\section{DISCUSSION}

In the absence of allometry, large specimens tend to have larger dimensions and have a greater deal of variance associated with overall size $[15,16,18]$. In order to minimize the effects of allometry, wing-tibia measurement data were $\log _{10}$ transformed [19], to equalize standard deviations across the differently sized variables and ensures multivariate normality of the data $[15,17,18]$.

Results of the GLM analyses of linear and ratio data revealed that different linear combinations can be used to characterize tsetse species populations. Most of the linear variables showed significant differences $(\mathrm{P}<0.0001)$ in size and shape among the populations. For example, the population from the lab colony ( $G$. m. morsitans) always stood out as the largest in most of the measured linear variables. The costa vein $(a b)$ and wing length $(a t)$ are the two main features that morphologically characterized the three tsetse fly species studied. The larger size observed in G. m. morsitans (lab colony) may be related to laboratory conditions, where optimal conditions like temperature (24 $29^{\circ} \mathrm{C}$ ), relative humidity of $60 \%$ are provided to the flies. In tsetse flies, colder environmental conditions increase metabolic rate as observed under typical forested regions in Africa [20]. This condition brings about larger body size possibly as a consequence of increased feeding requirements or liquid storage in the body of the flies. Variation observed among the different tsetse species populations was in line with work by Adeleke et al. [21] on populations of Culex quinquefasciatus and Mansonia africana in south- west Nigeria. Their results based on morphometric analyses on antennal length, proboscis length, fore-, mid and hind leg length, revealed variations in the two mosquito species, and concluded that wing length could be a good discriminating variable in characterizing members of complexes.

Separations along the first principal axes are usually attributed to overall size, while those along the second principal axes are attributed to shape [15, 16, 17]. The Principal components and canonical variate plots have demonstrated their worth as important taxonomic tools through evolutions of the role played by the overall body size in separating insect pests as well as vectors that are of medical importance [17].

The smallest Mahalanobis squared distance observed between G. p. palpalis (Eastern) and G. p. palpalis (Western) means that probably the two populations are more closely related morphologically compared to the other populations. The G. p. palpalis (Northern) skewing towards the negative axis on the PC1 and CV1 suggest that they were the smallest among the five populations, while G. $m$. morsitans having larger scatter points might also be the largest among the groups.

The lab population of G. m. morsitans was expected to be larger since it was maintained under optimal conditions with minimal stress as compared to G. p. palpalis populations in the wild. The G. p. palpalis were collected 
from three different regions in different agro-ecological zones, and they are expected to adapt to the zones. The Western and Eastern regions are considered to be the forested regions of the country where rainfall is high most times of the year. Climatic conditions in these two regions probably favour growth of the flies and hence size increase compared to the Northern population, where the climate is hot throughout the year. Similar results were obtained by Solano et al. [22], where significant differences were observed in G. $p$ gambiensis populations collected from regions in Burkina Faso and others from Senegal. The difference observed in G. p gambiensis populations from their findings was as a result of geographical distances between the sampling regions. Kandemir et al. [23] also carried out morphometric analyses on different population structures of dwarf honey bees (Apis florea Fabricius, 1876) in Iran. According to their findings, populations from different regions were significantly different based on characters observed in the fore- and hind wings of the insects. Several factors may be involved in morphological differences, such as geographical distances, ecological differences or even trapping methods. The variation in morphometric traits might also be an adaptation to the various Agro-Ecological Zones of the flies.

The results of the current study on principal components and canonical variates analyses suggest that the examined regional populations of $G$. p . palpalis can be categorized into different groups. As shown in figures $3 a$ and $b$, the Northern fly population was distinct from the other populations along the first two canonical variate axes. However the other populations, Eastern, lab colony and Western were not quite distinguishable from each other. It can be suggested that the Northern population had the least gene flow compared to the other populations because of geographical distances between them. This could also suggest that the amount of morphological differences could be predicted by the level of geographic isolation [24].

The G. m. morsitans (lab colony) was characterized morphometrically by the wing variables, $k g, j k, a d, g h, i j$ and $h i$ and stood out to be the largest in most cases. Wing length (at) and costa vein $(a b)$ morphometrically characterized the three tsetse species into separate group each. The principal components and canonical variates as well as Mahalanobis squared distances showed size differences among the different populations, which act to confirm linear and ratio separations. Therefore based on these differences in morphometric characters observed, the three tsetse species were distinguished from each other. Similar work on morphometrics needs to be done to include many other body parts such as proboscis length, antennal length, thorax and abdomen length and width in order to establish stronger morphometric tools for discriminating different tsetse fly species.

\section{ACKNOWLEDGEMENT}

Our sincere gratitude goes to all ARPPIS Lecturers and also the staff and management of Ghana Atomic Energy Commission (GAEC) for their immense contributions towards this work.

\section{FUNDING}

This work was funded by the German Academic Exchange Service (Deutscher Akademisher Austaucher Dienst e.v., DAAD), through the University of Ghana, Legon. I deeply owe you a life-long gratitude, and may God bless us all.

\section{REFERENCES}

[1] Jordan, A. M. (1986). Trypanosomiasis control and African rural development. New York: Longman Group Limited.

[2] Kabayo, J. P. (2002). Aiming to eliminate tsetse from Africa. Trends in Parasitology, 11: 473 - 475.

[3] Mahama, C. I., Mohammed, H. A., Abavana M., Sidibe I., Kone' A. (2003). Tsetse and Trypanosomoses in Ghana in the Twentieth Century: a Review. Review Elev Medical veterinary Pays tropical, 56: 27 - 32 .

[4] Ramatu, M. A. and Seidu, A. (2008). SocioEconomic Baseline survey report of the Upper West Region for the PATTEC project coordination Unit. Pong-Tamale, Ghana: Veterinary Services Department.

[5] Vreysen, M. J. B., Saleh K. M., Ali ,M. Y., Abdulla, A. M.; Zhu, Z. R, Juma, K. G., Dyck, V. A., Msangi, A. R., Mkonyi P. A. and Feldmann, F. U. (2002). Glossina austeni (Diptera: Glossinidae) eradicated on the island of Unguja, Zanzibar, using the Sterile Insect Technique. Journal of Economic and Entomology, 93: 123 - 135.

[6] Bouyer, J., Solano, P., Cuisance, D., Itard, J., Frézil, J.-L., and Authié, E., (2010). Trypanosomosis: Control methods., pp. 1936-1943. In: P.-C. Lefèvre, J. Blancou, R. Chermette G., Uilenberg [edis.], Infectious and parasitic diseases of livestock, Volume 2. Lavoisier (Tech and Doc), Paris.

[7] Torr, S. J.; Solano, P. (2010). Olfaction in Glossina-host interactions: a tale of two tsetse, $265-$ 289. In: Olfaction in vector hosts interactions: 
Ecology and control of vector borne diseases, Volume 2. Edited by Takken B. K. W. Wageningen University, Netherlands, $437 \mathrm{pp}$.

[8] Rohlf, F. J. and Marcus, L. F. (1993). A revolution in morphometrics. Trends in Ecology and Evolution 8: 129 - 132

[9] Vignon, M. and Sasal, P. (2010) The use of geometric morphometrics in understanding shape variability of sclerotized haptoral structures of monogeneans (Platyhelminthes) with insights into biogeographic variability. Parasitology International, 59: 183-191.

[10] Camara, M., Caro-Riano, H., Ravel, S., Dujardin, J. P., Hervouet, J.P., de Meeus, T., Kagbadouno, M. S., Bouyer, J. and Solano, P. (2006). Genetic andmorphometric evidence for isolation of a tsetse (Diptera: Glossinidae) population (Loos islands, Guinea), Journal of Medical Entomology 43(5): 853 860.

[11] Kagbadouno, M., Camara, M., Bouyer, J., Hervouet, J. P., Morifaso, O.; Kaba, D.; Jamonneau, V.and Solano, P. (2009). Tsetse elimination: its interest and feasibility in the historical sleeping sickness focus of Loos islands, Guinea. Parasite, 16: 29 - 36.

[12] Solano, P., Bouyer, J., Itard, J. and Cuisance, D. (2010). Cyclical vectors of trypanosomosis, pp. 153 181. In: Infectious and parasitic diseases of livestock (Vol. 1), Chapter 012, P. C. Lefèvre, J. Blancou, R. Chermette and G. Uilenberg (Editors). Lavoisier (Tec and Doc), Paris.

[13] Bookstein F. L. (1991) Morphometric tools for landmark data. Cambridge University Press, Cambridge, xvii, 435 pp.

[14] Kimani-Njougu, S. W., Trostle, M. K., Wharton, R. A., Woolley, J. B. and Raspi, A. (2001) Biosystematics of the Psyttalia concolor species complex (Hymenoptera: Braconidae: Opiinae): the Identity of populations attaching Ceratitis capitata (Diptera: Tephritidae) in coffee in Kenya. Biological Control, 20: 167 - 174.

[15] Billah, M. K. (2004). Biosystematic studies of Psyttalia species (Hymenoptera: Braconidae): Parasitoids attacking fruit infesting flies (Diptera: Tephritidae) in Africa. 236 pp. PhD thesis, University of Ghana, Legon-Accra.

[16] Billah, M. K., Kimani-Njogu, S., Overholt, W. A., Wharton, R. A. Wilson, D. D. and Cobblah, M. A. (2005). The effect of host larvae on three (Psyttalia species) (Hymenoptera: Braconidae): parasitoids of fruit-infesting flies (Diptera: Tephritidae). International Journal of Tropical Insect Science 25(3): $168-175$.

[17] 17. Billah, M. K. Kimani-Njogu, S. W., Wharton, R. A., Woolley J. B. and Masiga, D. (2008). Comparison of five allopatric fruit fly parasitoid populations (Psyttalia species) (Hymenoptera: Braconidae) from coffee fields using morphometric and molecular methods. Bulletin of Entomological Research, 98: 63 - 75 Cambridge University Press.

[18] Woolley, J. B., Rose, M. and Krauter, P. (1994). Morphometric comparisons of Aphytis species in the lingnanensis group (Hymenoptera: Aphelinidae). pp. 223 - 244. In: Rosen, D. (Editor.) Advances in Aphytis Research. Andover, Intercept Limited UK.

[19] Sokal R. R. and Rohlf, F. J. (1995). Biometry: The principles and Practice of Statistics in Biological Research. 3rd Edition. W. H. Freeman and Company, USA. $887 \mathrm{pp}$.

[20] Terblanche, J. S.; Klok, C, J., Chow, S. L. (2005). Temperature-dependence of metabolic rate in Glossina morsitans morsitans (Diptera, Glossinidae) does not vary with gender, age, feeding, pregnancy or acclimation. Journal of Insect Physiology, 51: 861 870.

[21] Adeleke, M. A., Mafiana, C. F., Idowu, A. B., Adekunle, M. F. and Dansu, B. M. (2008) Morphometric studies on Culex quinquefasciatus and Mansonia africana (Diptera: Culicidae) in Abeokuta, south-western Nigeria. Tanzania Journal of Health Research, (10): 2.

[22] Solano, P., S. de La Rocque, T. de Meeu“ s, G. Cuny, G. Duvallet, and Cuisance D. (2000). Microsatellite DNA markers reveal genetic differentiation among populations of Glossina palpalis gambiensis collected in the agropastoral zone of Sideradougou, Burkina Faso. Insect Molecular Biology, 9: 433 - 439

[23] Kandemir, I., Moradi, G. M., Ozden, B. and Ozkan, A. (2009). Wing geometry as a tool for studying the population structure of dwarf honey bees (Apis florea Fabricius 1876) in Iran. Apicultural Research, 48: 238 - 246.

[24] Dujardin, J. P., Panzera, P., Schofield C. J. (1999) Triatominae as a model of morphological plasticity under ecological pressure Mem. Inst. Oswaldo Cruz, 94 (1999): 223 - 228 